\title{
Kernos
}

Revue internationale et pluridisciplinaire de religion grecque antique

3| 1990

Varia

\section{Jacques DESAUTELS, Dieux et mythes de la Grèce ancienne. La mythologie gréco-romaine}

\section{André Motte}

\section{OpenEdition \\ Journals}

\section{Édition électronique}

URL : http://journals.openedition.org/kernos/1026

DOI : 10.4000/kernos. 1026

ISSN : 2034-7871

\section{Éditeur}

Centre international d'étude de la religion grecque antique

\section{Édition imprimée}

Date de publication : 1 janvier 1990

ISSN : 0776-3824

\section{Référence électronique}

André Motte, « Jacques desAutels, Dieux et mythes de la Grèce ancienne. La mythologie grécoromaine », Kernos [En ligne], 3| 1990, mis en ligne le 19 avril 2011, consulté le 21 septembre 2020. URL : http://journals.openedition.org/kernos/1026 ; DOI : https://doi.org/10.4000/kernos.1026 
seulement sur la culture de ceux qui l'ont créé, mais aussi sur le développement artistique aux âges ultérieurs.

Un point important qui n'a pas été négligé, comme c'est le cas dans la plupart des encyclopédies, est qu'une bibliographie internationale figure au terme de chaque article, outre la bibliographie générale à la fin du tome.

Une aide considérable à la recherche d'un motif ( $p$. ex. sacrifice humain, parricide) est aussi apportée par l'index thématique qui s'ajoute aux cartes, tableaux généalogiques et autres outils offerts aux lecteurs.

En ce qui concerne l'illustration, les représentations les plus expressives des mythes, de même que des attestations de leur développement à travers les siècles et les civilisations, ont été extraites des musées et des collections privées.

Cette fois encore, le public déjà habitué à la qualité des œuvres publiées par l'Ekdotiké Athénon ne sera pas déçu : les difficultés que l'on peut éprouver à s'orienter dans l'univers compexe de la mythologie, surtout en dehors du domaine greco-romain, sont ici surmontées, et l'on peut dire que les auteurs ont réussi à traiter, dans les limites étroites d'articles encyclopédiques, une information aussi complète que possible, réalisant ainsi le but éducatif visé.

Aikaterini LEFKA

Jacques DESAUTELS, Dieux et mythes de la Grèce ancienne. La mythologie gréco-romaine, Québec, Les Presses de l'Université Laval, 1988, 648 p., 129 ill., $17 \times 24,5 \mathrm{~cm}$.

La mythologie expliquée, et pas seulement contée, tel est le propos de cet important ouvrage, né d'un enseignement qui fut professé à l'Université Laval et prolongé par un série d'émissions télévisées. C'est dire que l'A. s'adresse ici à un large public et que les préoccupations didactiques l'emportent sur la recherche d'interprétations nouvelles. La démarche n'en est pas pour autant dépourvue d'originalité. À la différence de la plupart des dictionnaires et encyclopédies qui traitent du sujet, les principaux mythes du répertoire ancien sont ici regroupés dans différents thèmes, ce qui permet d'en montrer les interrelations. La matière est ainsi répartie en 11 chapitres dont les deux premiers sont introductifs et visent, d'une part, à une présentation générale de la mythologie gréco-romaine, dans son contexte religieux notamment, et, d'autre part, à une réflexion sur la notion de mythe et de mythologie faisant état des principaux courants modernes d'interprétation. Les chapitres suivants concernent successivement les cosmogonies, la théogonie hésiodique, les mythes de souveraineté et les légendes royales, l'anthropogonie, le mariage et l'amour, les divinités et les héros guerriers, les divinités techniciennes et les héros à mètis, les mythes liés à 
la fécondité et à la fertilité (Déméter et Dionysos) et enfin «la divinité grecque par excellence, Apollon». Pareille classification ne peut certes prétendre épuiser toute la riche diversité de la mythologie antique, mais elle permet au moins d'en faire voir des traits essentiels; si elle entraîne quelques redites et conduit parfois à accentuer tels aspects de certains mythes au détriment d'autres, elle offre l'avantage d'une mise en perspective éclairante qui intègre l'apport de nombreux travaux modernes.

Brièvement introduits et suivis d'une conclusion récapitulative, les chapitres sont illustrés par de nombreux extraits de poètes anciens, sobrement annotés et commentés avec compétence; ils sont aussi accompagnés d'une bibliographie sommaire dont la plupart des titres sont en langue française. Diverses annexes enrichissent l'ouvrage; elles comprennent notamment un tableau des grandes divinités, avec indication de leurs symboles, de leurs fonctions et de leurs principaux lieux de culte, des tableaux généalogiques, un index des auteurs anciens cités, un index des noms propres ainsi qu'une table des illustrations; abondantes, mais d'un format qui paraîtra souvent trop réduit, les représentations, en noir et blanc, sont puisées pour la plupart dans le trésor de l'iconographie gréco-romaine.

Voici donc un ouvrage de haute vulgarisation scientifique qui non seulement se prête à la consultation, mais qui invite aussi à la lecture. On doit lui souhaiter une large audience, car il contribue à faire mieux comprendre la mythologie antique dans la dimension religieuse qui la caractérise au départ, dans la réflexion permanente sur l'homme, la société et le monde qu'elle reflète, dans la vitalité aussi qu'elle conserve au sein de la culture occidentale. Les spécialistes ne doivent pas s'attendre à y découvrir de grandes nouveautés, mais ils y trouveront souvent matière à réflexion et ils ne seront pas davantage insensibles au plaisir que procure la lecture d'une œuvre bien écrite, que recommandent aussi son ordonnance méthodique ainsi que sa présentation soignée.

André MOTTE

Marcel DETIENNE et Giulia SISSA, La vie quotidienne des dieux grecs, Paris, Hachette, 1989, 301 p., 12 pl., 2 cartes, 13 x 20 cm. Prix : 118 FF.

L'Iliade d'Homère autorise, d'après les A., l'écriture d'une Vie quotidienne des dieux et donc l'insertion de cet ouvrage au sein de la collection Hachette du même nom. Dès lors, toute la première partie, intitulée "Homère anthropologue", est une lecture attentive du récit de la Guerre de Troie dans le but de disséquer au jour le jour l'existence de la société des Immortels : sentiments, besoins, morphologie, occupations, exercice du pouvoir et rapports aux hommes sont étudiés à travers les différents épisodes, petits et grands, du récit homérique. L'anthropo- 